Case Report

\title{
Understanding Cerebellar Liponeurocytomas: Case Report and Literature Review
}

\author{
M. Y. Oudrhiri, N. Raouzi, I. El Kacemi, N. El Fatemi, R. Gana, \\ M. R. Maaqili, and F. Bellakhdar
}

Neurosurgery Department, Hopital Ibn Sina, P.O. Box 20503 Hay Riad, 10104 Rabat, Morocco

Correspondence should be addressed to M. Y. Oudrhiri; yassaad.oudrhiri@gmail.com

Received 11 October 2013; Accepted 10 December 2013; Published 8 January 2014

Academic Editors: K. Arnautovíc, J. E. Cohen, J. C. Kattah, R. Koide, V. Rajajee, and D. J. Rivet

Copyright (C) 2014 M. Y. Oudrhiri et al. This is an open access article distributed under the Creative Commons Attribution License, which permits unrestricted use, distribution, and reproduction in any medium, provided the original work is properly cited.

Cerebellar liponeurocytomas were recognized in the $2000 \mathrm{WHO}$ 3rd edition of CNS tumors as a distinct grade I pathological entity, a tumor with a more favorable prognosis than medulloblastoma. But reports of long-term recurrences and some possible aggressive behavior led to an upgrade on the latest WHO 4th edition of CNS tumors. The case of a 64-year-old female patient is reported in this paper. More than 30 cases of this lately recognized pathological entity have been reported to date. The diagnostic, radiological, and pathological features associated with this tumor are discussed through a literature review.

\section{Introduction}

The cerebellar liponeurocytoma was first included in the 2000 World Health Organisation's (WHO) 3rd edition of Central Nervous System (CNS) tumors' classification as a separate grade I entity. Thanks to a better recognition and longer follow-up, evidences of a possible tumor recurrence were growing. Rates of recurrences were estimated to $60 \%$ during follow-up, with some cases presenting even an aggressive behavior [1-3]. This way, the cerebellar liponeurocytoma was upgraded II on the 2007 WHO's 4th edition of CNS tumors' classification.

Through this case report we reviewed the literature for a better understanding of this pathology and the controversy around, with a listing of published cases of cerebellar liponeurocytoma.

\section{A Case Report}

A 64-year-old woman, with a 10-year history of Parkinson's disease, was admitted to our department for a 7-month clinical course of progressive worsening, right-sided weakness, and signs of increased intracranial pressure.

On examination, her consciousness was clear, and, beside the Parkinson's related tremor, she had a mild right hemiparesia (3/5) with a right Babinski sign and hyperreflexia on the right side. Ocular investigations showed bilateral papilledema and horizontal nystagmus.

MRI scan showed a $60 \times 40 \times 42 \mathrm{~mm}$ heterogeneous, enhancing lesion of the right cerebellum extending to the CPA (cerebellopontine angle), causing mass effect and mild hydrocephalous.

On T1-weighted images (Figure 1(a)) the mass was isointense to brain tissue, with sparse, hyperintense areas that turned hypointense on FAT-SAT sequences (Figure 1(b), arrow).

Irregular enhancement was noted after gadolinium administration (Figure 1(c)). There was no associated edema.

The patient underwent surgery through a retrosigmoid approach. It discovered a soft grey tumor, with yellowish areas, and globally well circumscribed. The anterior part of the tumor was encasing cranial nerves and was infiltrative toward the brainstem, which only allowed for near total removal. No cerebrospinal fluid shunt was decided.

Pathological examination with immunohistochemical study revealed a tumor with astrocytic and neuronal differentiation (GFAP-NSE-synaptophysin positive) in which some focal areas of lipomatous differentiation were identified; the MIB-1 index was $<1 \%$; there was no cellular immaturity or necrosis, concluding on a cerebellar liponeurocytoma (WHO grade II) (Figure 2). 


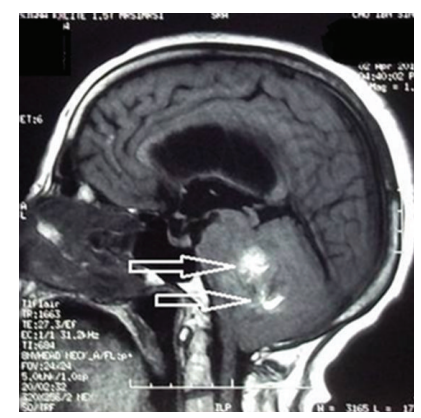

(a)

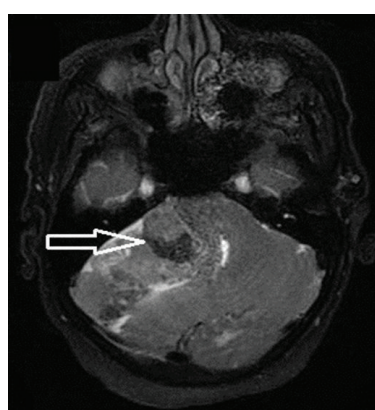

(b)

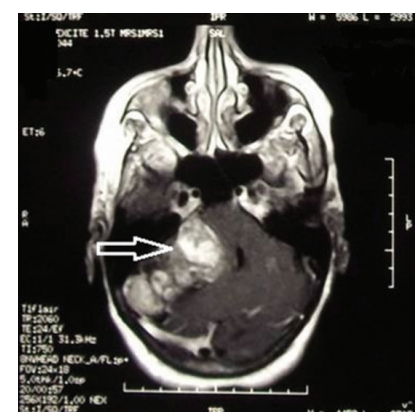

(c)

FIGURE 1: MRI of the brain in sagittal T1 (a), axial fat sat sequence (b), and axial T1 with gadolinium, respectively (c). Note the fat component (arrows in (a) and (c)) that turns hypointense after fat exclusion (arrow in (b)).

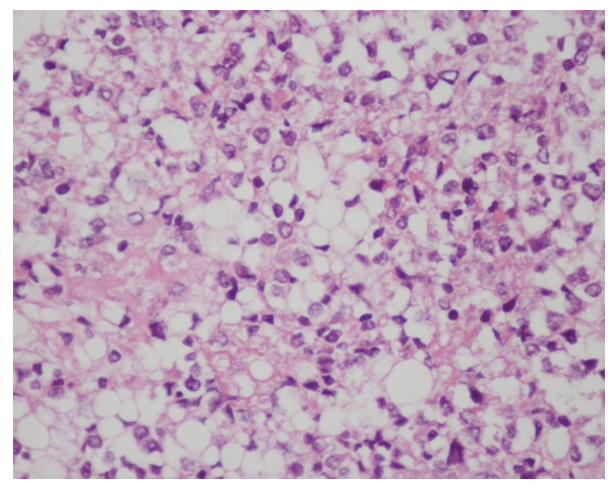

FIGURE 2: Histology results showing a typical field of liponeurocytoma; small round cells admixed with lipomatous cells. HES, original magnification $\times 10$.

The postoperative course was free of complications and the patient was discharged from hospital to the postoperative care unit for physical rehabilitation. No adjuvant therapy was decided.

At two-year follow-up, the patient's condition was fair with no motor deficit and better autonomy (Karnofsky index improved from 40 to $70 \%$ ).

\section{Discussion}

The cerebellar liponeurocytoma (LNC), as defined by the WHO, is a "rare, well differentiated neurocytic tumor of the cerebellum that arises in adults and typically shows focal or regional lipomatous differentiation. It has a low proliferative potential and a more favorable prognosis especially when compared to medulloblastoma (MDB), from which it needs to be distinguished" $[4,5]$. In addition, the genetic profile of LNC is different from the medulloblastoma's but close to the central neurocytoma's profile (except for the presence of TP53 mutation, absent in the later), which comforts the definition of cerebellar LNC as a separate pathological entity [6]. The association with a Parkinson disease was never reported; this may be incidental with no physiopathological correlation.
3.1. History. The cerebellar liponeurocytoma was first described in 1978, in a 44-year-old patient. Bechtel et al. named it "lipomatous medulloblastoma" and pointed to its better prognosis [7]. Since then, many other terms have been used to give name to this rare tumor: neurolipocytoma [8], medullocytoma [6], lipidized medulloblastoma [9], and lipomatous glioneurocytoma [10]. In 2000, the WHO adopted the term of "cerebellar liponeurocytoma" to replace all others.

3.2. Literature Review. Relying on a Pubmed research of Medline's database (using the keywords: lipidized medulloblastoma, medullocytoma, neurolipocytoma, and liponeurocytoma), we found 36 effective cases of pure cerebellar liponeurocytoma reported till now (Table 1). Controversy is rising on whether to consider cases exclusively located to the 4th ventricle and meeting the histological criteria of cerebellar liponeurocytoma as such or as central liponeurocytomas. Believing not and referring to the WHO's definition, the cases of Fung et al., Hsu et al., and Owler et al. were not included in our review [11-13]. To avoid this confusion, Chakraborti et al. suggests the designation "liponeurocytoma" rather than the restricted "cerebellar liponeurocytoma" to include other locations on the 4 th and lateral ventricles [14].

Epidemiological analysis places cerebellar LNC as a tumor of adulthood (fourth and fifth decades), with mean age of 49 years (range from 32 to 74 years). The sex ratio, based on our review, shows a clear female prevalence $(1: 1.8)$. Giordana et al. and Sharma et al. reported cases of childhood onset, but these are more likely MDB with lipidized cells than lipomatous MDB $[15,16]$.

It is a tumor of the cerebellar hemispheres; location on the vermis is not unusual and so is the extension to the CPA, and was reported by many authors [17-19]. Two cases of supra-tentorial extension from cerebellar LNC were reported $[19,20]$. Spinal extension to the C1-C2 space from cerebellar LNC was reported in two cases $[18,21]$. One case of spinal lumbar metastasis occurring 11 years after initial diagnosis was reported [19].

On MRI scan, these tumors are globally heterogeneous, iso-, or hypointense on T1-weighted images, with areas of high signal intensity. These areas turn hypointense on 


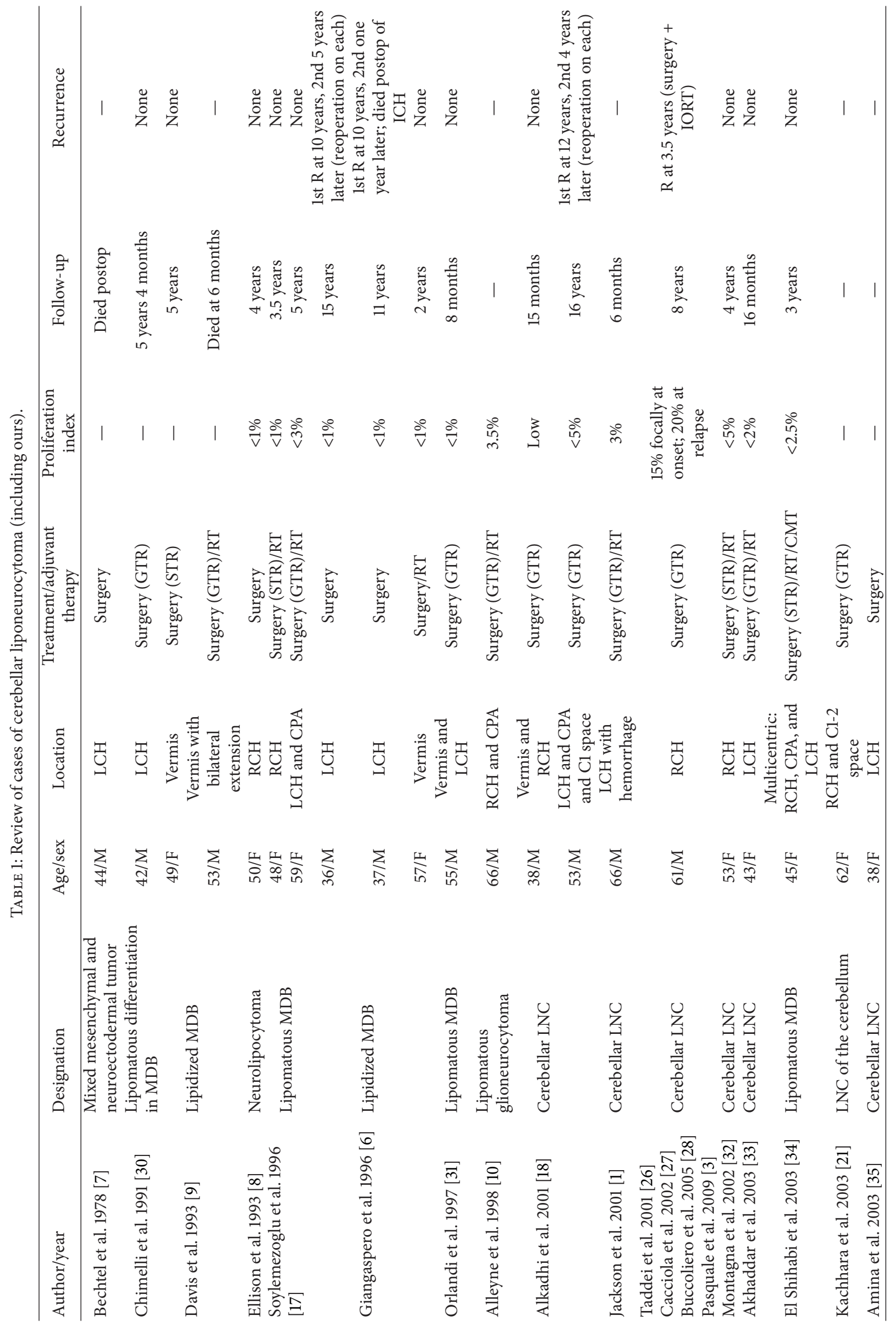




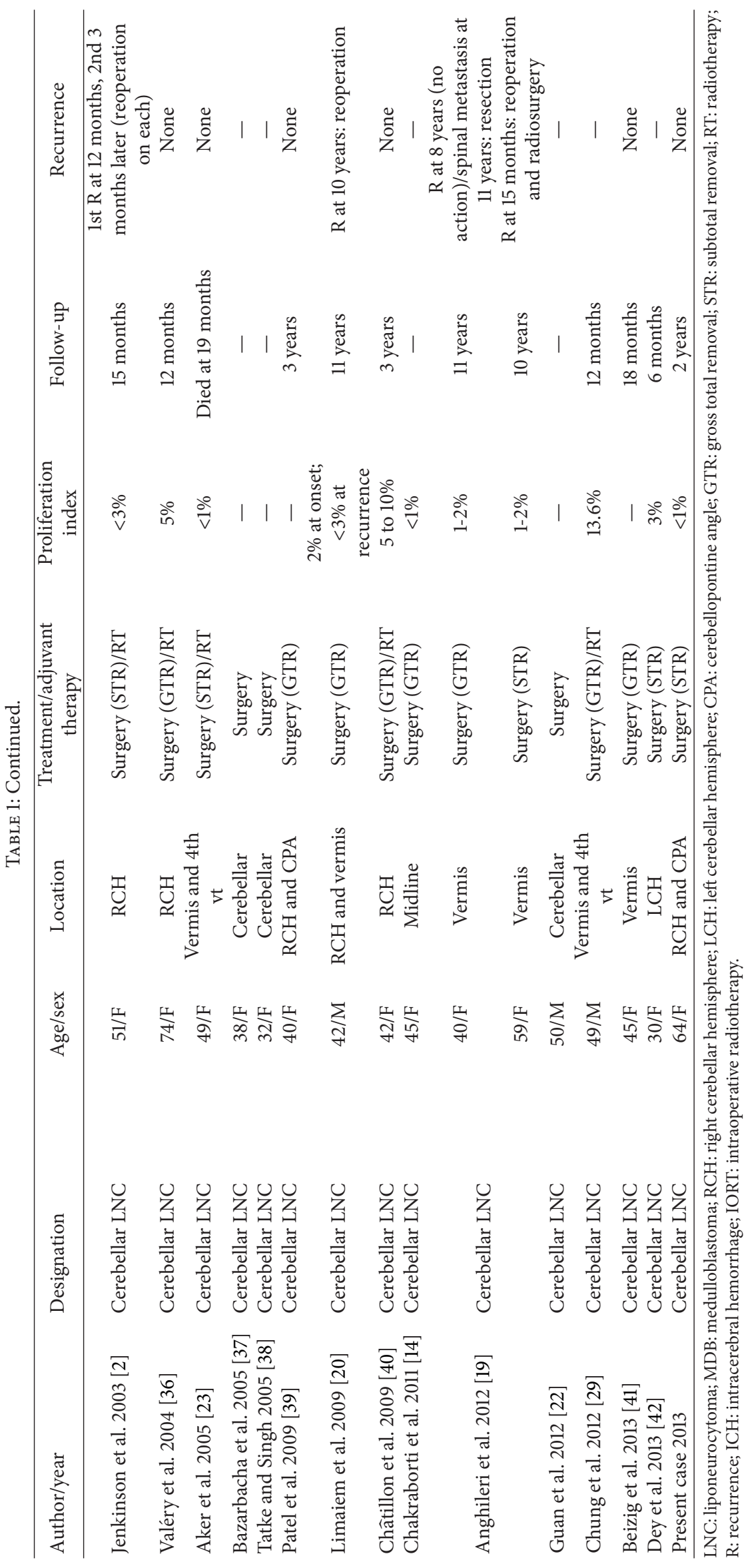


fat suppression sequences, which may be very suggestive although there is no specific radiological behavior. Contrast enhancement is usually present and reported as irregular and heterogeneous; on T2-weighted images, the solid component is slightly hyperintense with focal pronounced hyperintense areas corresponding to fat. Some cystic components may be present, but usually no edema is reported [22].

One case of central tumor hemorrhage was reported on radiological findings [1].

3.3. Pathology and Genetics. Typically, cerebellar LNC is a glioneuronal tumor with lipidized neoplastic cells that resemble mature adipocytes. These are interspersed throughout the lesion. Areas of neuronal differentiation are usually positive for immunochemistry neuronal markers (synaptophysin; MAP-2). Reactivity for GFAP was also described [23-25]. No mitosis, necrosis, or vascular hyperplasia is usually seen.

Proliferation index, as measured by Ki-67/MIB-1, is usually low $(<5 \%)$ in most published cases $[1,5,6,10,17,20,23]$, which comforts the interpretation of the lesion as a benign one. However, many recent papers of separate cases reported relatively high rates of $\mathrm{Ki}-67$ with cytopathologic atypia. These cases were associated with high rates of recurrences and a more aggressive behavior [3, 26-29]. Based on an analysis of relapse cases, some authors suggested the existence of different grades of malignancy of the $\operatorname{LNC}[3,28]$.

To date, no specific genetic marker has been clearly identified. However, in their recently published paper, Anghileri et al. found a significantly positive overexpression of two possible markers: NEUROG1 and FABP4 [19]. Further studies may assess these findings.

3.4. Treatment. Optimum treatment modality is still a matter of debate. If all recommend surgery as the initial management, postoperative radiotherapy does not make the unanimity. In fact, the lack in understanding the tumor's biological behavior led to various therapeutic approaches.

The strong belief of it being a benign tumor often led surgeons not to choose adjuvant therapies whatever the extent of resection was. Moreover, the absence of histopathological patterns of malignancy comforted this attitude [27]. Further publications with long follow-up reported recurrence rates as high as $30-50 \%$ in the surgery groups with a median time to relapse of 10 years $[3,27,28]$. Limaiem et al. reported a rate of $31 \%$ based on an analysis of relapse cases [20].

The efficacy and the need for postoperative radiotherapy are still unclear. The scarcity of the tumor does not allow structured studies, and radiotherapy was used in many ways (EBRT; IORT) with different follow-up periods which makes literature very inhomogeneous. In fact, it seems not to prevent early recurrence [2]. The place of radiosurgery, given the low proliferative rate of these tumors, also needs to be established.

Management of recurrence is also debatable, but radiotherapy following reoperation seems to be more appropriate especially when secondary aggressive features are observed.

Our patient did not receive postoperative radiotherapy based on the belief that radiotherapy is to be a recurrence modality management after reoperation as for Cacciola et al. [27].
3.5. Survival. To date, the longest survival time recorded is of 18 years in two patients $[17,18]$; both were treated with surgery only, even on relapse.

\section{Conclusion}

All this data analysis makes the prognosis and the evolution of this tumor still unpredictable. Its management is more debatable but all agree on a large surgical removal and a long follow-up. Adjuvant radiotherapy may be indicated if subtotal removal was performed or only on relapse after reoperation.

This paper represents an up-to-date literature review of all published cases of cerebellar liponeurocytoma.

\section{Conflict of Interests}

The authors declare that there is no conflict of interests regarding the publication of this paper.

\section{References}

[1] T. R. Jackson, W. F. Regine, D. Wilson, and D. G. Davis, "Cerebellar liponeurocytoma: case report and review of the literature," Journal of Neurosurgery, vol. 95, no. 4, pp. 700-703, 2001.

[2] M. D. Jenkinson, J. J. D. Bosma, D. Du Plessis et al., "Cerebellar liponeurocytoma with an unusually aggressive clinical course: case report," Neurosurgery, vol. 53, no. 6, pp. 1425-1428, 2003.

[3] G. Pasquale, B. A. Maria, P. Vania, P. Gastone, and D. L. Nicola, "Cerebellar liponeurocytoma: an updated follow-up of a case presenting histopathological and clinically aggressive features," Neurology India, vol. 57, no. 2, pp. 194-196, 2009.

[4] D. J. Brat, J. E. Parisi, B. K. Kleinschmidt-DeMasters et al., "Surgical neuropathology update: a review of changes introduced by the WHO classification of tumours of the central nervous system, 4th edition," Archives of Pathology and Laboratory Medicine, vol. 132, no. 6, pp. 993-1007, 2008.

[5] P. Kleihues, L. Chimelli, F. Giangaspero, and H. Ohgaki, "Cerebellar liponeurocytoma," in WHO Classification of Tumours of the Central Nervous System, P. Kleihues and W. K. Cavenee, Eds., pp. 110-112, IARC Press, Lyon, France, 2007.

[6] F. Giangaspero, G. Cenacchi, F. Roncaroli et al., "Medullocytoma (lipidized medulloblastoma): a cerebellar neoplasm of adults with favorable prognosis," American Journal of Surgical Pathology, vol. 20, no. 6, pp. 656-664, 1996.

[7] J. T. Bechtel, J. M. Patton, and Y. Takei, "Mixed mesenchymal and neuroectodermal tumor of the cerebellum," Acta Neuropathologica, vol. 41, no. 3, pp. 261-263, 1978.

[8] D. W. Ellison, S. C. Zygmunt, and R. O. Weller, "Neurocytoma/ lipoma (neurolipocytoma) of the cerebellum," Neuropathology and Applied Neurobiology, vol. 19, no. 1, pp. 95-98, 1993.

[9] D. G. Davis, D. Wilson, M. Schmitz, and W. R. Markesbery, "Lipidized medulloblastoma in adults," Human Pathology, vol. 24, no. 9, pp. 990-995, 1993.

[10] C. H. Alleyne Jr., S. Hunter, J. J. Oison, and D. L. Barrow, "Lipomatous glioneurocytoma of the posterior fossa with divergent differentiation: case report," Neurosurgery, vol. 42, no. 3, pp. 639-643, 1998.

[11] K.-M. Fung, W. Fang, R. E. Norton, N. Tortes, A. Chu, and L. A. Langford, "Cerebellar central liponeurocytoma," Ultrastructural Pathology, vol. 27, no. 2, pp. 109-114, 2003. 
[12] P.-W. Hsu, T.-C. Hsieh, C.-N. Chang et al., "Fourth ventricle central neurocytoma: case report," Neurosurgery, vol. 50, no. 6, pp. 1365-1367, 2002.

[13] B. K. Owler, J. M. Makeham, M. Shingde, and M. Besser, "Cerebellar liponeurocytoma," Journal of Clinical Neuroscience, vol. 12, no. 3, pp. 326-329, 2005.

[14] S. Chakraborti, A. Mahadevan, A. Govindan et al., "Supratentorial and cerebellar liponeurocytomas: report of four cases with review of literature," Journal of Neuro-Oncology, vol. 103, no. 1, pp. 121-127, 2011.

[15] M. T. Giordana, P. Schiffer, A. Boghi, P. Buoncristiani, and F. Benech, "Medulloblastoma with lipidized cells versus lipomatous medulloblastoma," Clinical Neuropathology, vol. 19, no. 6, pp. 273-277, 2000.

[16] M. C. Sharma, M. Agarwal, A. Suri, S. Gaikwad, P. Mukhopadhyay, and C. Sarkar, "Lipomedulloblastoma in a child: a controversial entity," Human Pathology, vol. 33, no. 5, pp. 564-569, 2002.

[17] F. Soylemezoglu, D. Soffer, B. Onol, K. Schwechheimer, and P. Kleihues, "Lipomatous medulloblastoma in adults: a distinct clinicopathological entity," American Journal of Surgical Pathology, vol. 20, no. 4, pp. 416-418, 1996.

[18] H. Alkadhi, M. Keller, S. Brandner, Y. Yonekawa, and S. S. Kollias, "Neuroimaging of cerebellar liponeurocytoma," Journal of Neurosurgery, vol. 95, no. 2, pp. 324-331, 2001.

[19] E. Anghileri, M. Eoli, R. Paterra et al., "FABP4 is a candidate marker of cerebellar liponeurocytomas," Journal of NeuroOncology, vol. 108, pp. 513-519, 2012.

[20] F. Limaiem, S. Bellil, I. Chelly et al., "Recurrent cerebellar liponeurocytoma with supratentorial extension," Canadian Journal of Neurological Sciences, vol. 36, no. 5, pp. 662-665, 2009.

[21] R. Kachhara, R. N. Bhattacharya, S. Nair, and V. V. Radhakrishnan, "Liponeurocytoma of the cerebellum-a case report," Neurology India, vol. 51, no. 2, pp. 274-276, 2003.

[22] J. T. Guan, Y. Q. Geng, Y. Cheng, Y. L. Guo, and R. L. Wu, "Magnetic resonance imaging of cerebellar liponeurocytoma. A case report and review of the literature," Journal of Neuroradiology, vol. 25, no. 3, pp. 331-336, 2012.

[23] F. V. Aker, S. Özkara, P. Eren, Ö. Peker, S. Armaǧan, and T. Hakan, "Cerebellar liponeurocytoma/lipidized medulloblastoma. Case report and review of the literature," Journal of NeuroOncology, vol. 71, no. 1, pp. 53-59, 2005.

[24] S. Hostmann, A. Perry, G. Reifenberger et al., "Genetic and expression profiles of cerebellar liponeurocytomas," Brain Pathology, vol. 14, no. 3, pp. 281-289, 2004.

[25] T. Nishimoto and B. Kaya, "Cerebellar liponeurocytoma," Archives of Pathology \& Laboratory Medicine, vol. 136, pp. 965969, 2012.

[26] G. L. Taddei, A. M. Buccoliero, A. Caldarella et al., "Cerebellar liponeurocytoma: Immunohistochemical and ultrastructural study of a case," Ultrastructural Pathology, vol. 25, no. 1, pp. 5963, 2001.

[27] F. Cacciola, R. Conti, G. L. Taddei, A. M. Buccoliero, and N. Di Lorenzo, "Cerebellar liponeurocytoma: case report with considerations on prognosis and management," Acta Neurochirurgica, vol. 144 , no. 8, pp. 829-833, 2002.

[28] A. M. Buccoliero, A. Caldarella, S. Bacci et al., "Cerebellar liponeurocytoma: morphological, immunohistochemical, and ultrastructural study of a relapsed case," Neuropathology, vol. 25, no. 1, pp. 77-83, 2005.
[29] S. B. Chung, Y. L. Suh, and J. I. Lee, "Cerebellar liponeurocytoma with an unusually aggressive histopathology: case report and review of the literature," Journal of Korean Neurosurgical Society, vol. 52, no. 3, pp. 250-253, 2012.

[30] L. Chimelli, M. D. Hahn, and H. Budka, "Lipomatous differentiation in a medulloblastoma," Acta Neuropathologica, vol. 81, no. 4, pp. 471-473, 1991.

[31] A. Orlandi, B. Marino, M. Brunori, R. Greco, and L. G. Spagnoli, "Lipomatous medulloblastoma," Clinical Neuropathology, vol. 16, no. 4, pp. 175-179, 1997.

[32] N. Montagna, D. Moreira, L. C. Vaz, and M. Reis, "Cerebellar liponeurocytoma: a newly recognized clinico-pathological entity," Arquivos de Neuro-Psiquiatria, vol. 60, no. 3, pp. $725-$ 729, 2002.

[33] A. Akhaddar, I. Zrara, M. Gazzaz, B. El Moustarchid, S. Benomar, and M. Boucetta, "Cerebellar liponeurocytoma (lipomatous medulloblastoma)," Journal of Neuroradiology, vol. 30, no. 2, pp. 121-126, 2003.

[34] S. Elshihabi, M. Husain, and M. Linskey, "Lipomatous medulloblastoma: a rare adult tumor variant with a uniquely favorable prognosis," Surgical Neurology, vol. 60, no. 6, pp. 566-570, 2003.

[35] M. Amina, B. Saadia, N. Kais et al., "Cerebellar liponeurocytoma: a case report and review of the literarute," Pathologica, vol. 95, no. 6, pp. 456-459, 2003.

[36] C. A. Valéry, L. J. Sakka, and J. Poirier, "Problematic differential diagnosis between cerebellar liponeurocytoma and anaplastic oligodendroglioma," British Journal of Neurosurgery, vol. 18, no. 3, pp. 300-303, 2004.

[37] H. M. Bazarbacha, S. Nagi, W. Zouauoi, L. Belghith, R. Sebai, and S. Touibi, "Cerebellar liponeurocytoma. Case report," Tunisie Medicale, vol. 83, no. 2, pp. 120-122, 2005.

[38] M. Tatke and A. K. Singh, "Cerebellar liponeurocytoma-a case report," Indian Journal of Pathology and Microbiology, vol. 48, no. 1, pp. 29-31, 2005.

[39] N. Patel, A. Fallah, J. Provias, and N. K. Jha, "Cerebellar liponeurocytoma," Canadian Journal of Surgery, vol. 52, no. 4, pp. E117-E119, 2009.

[40] C. E. Châtillon, M. C. Guiot, D. Roberge, and R. Leblanc, "Cerebellar liponeurocytoma with high proliferation index: treatment options," Canadian Journal of Neurological Sciences, vol. 36, no. 5, pp. 658-661, 2009.

[41] N. Beizig, S. Ziadi, M. Ladib, and M. Mokni, "Cerebellar liponeurocytoma: case report," Neurochirurgie, vol. 59, pp. 3942, 2013.

[42] S. Dey, M. K. Chaudhury, S. K. Basu et al., "Cerebellar liponeurocytoma," Archives of Iranian Medicine, vol. 16, no. 3, pp. 199200, 2013. 


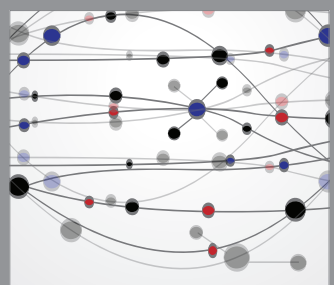

The Scientific World Journal
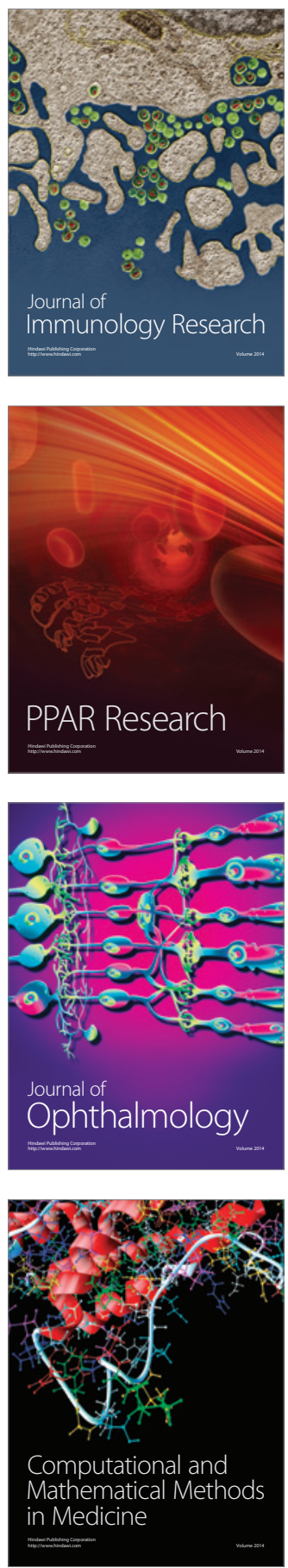

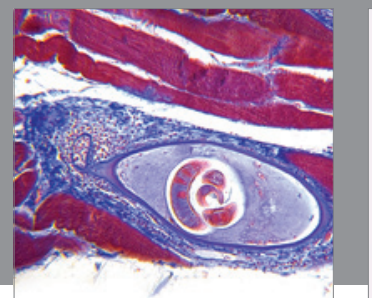

Gastroenterology

Research and Practice
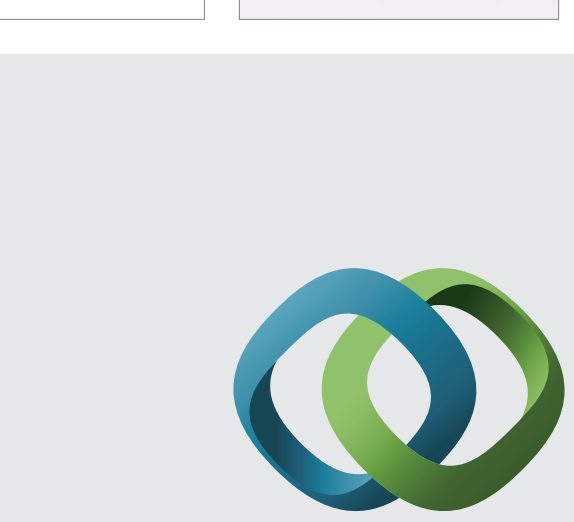

\section{Hindawi}

Submit your manuscripts at

http://www.hindawi.com
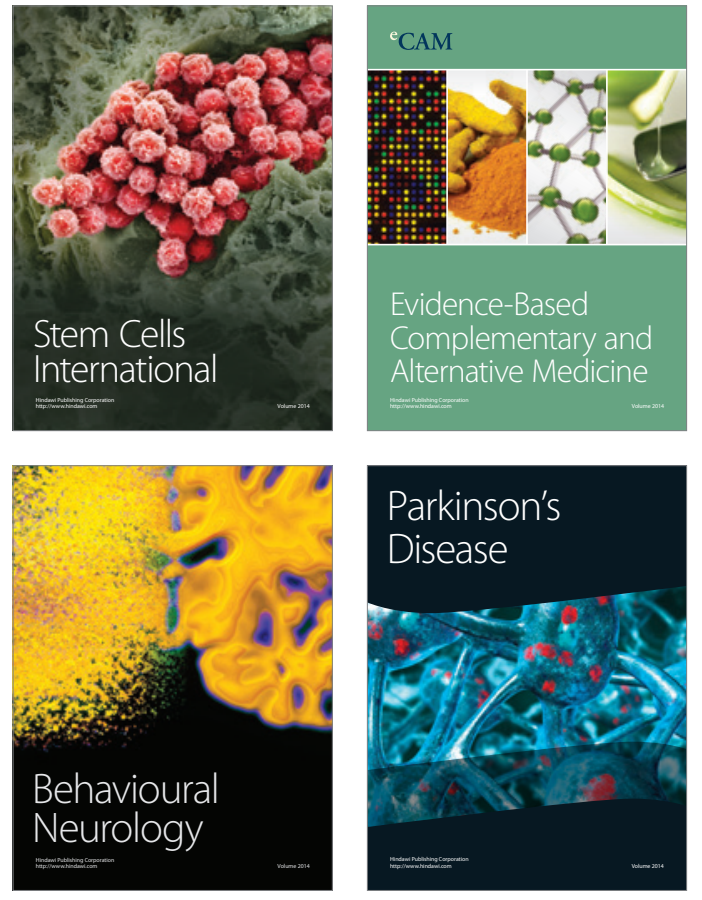
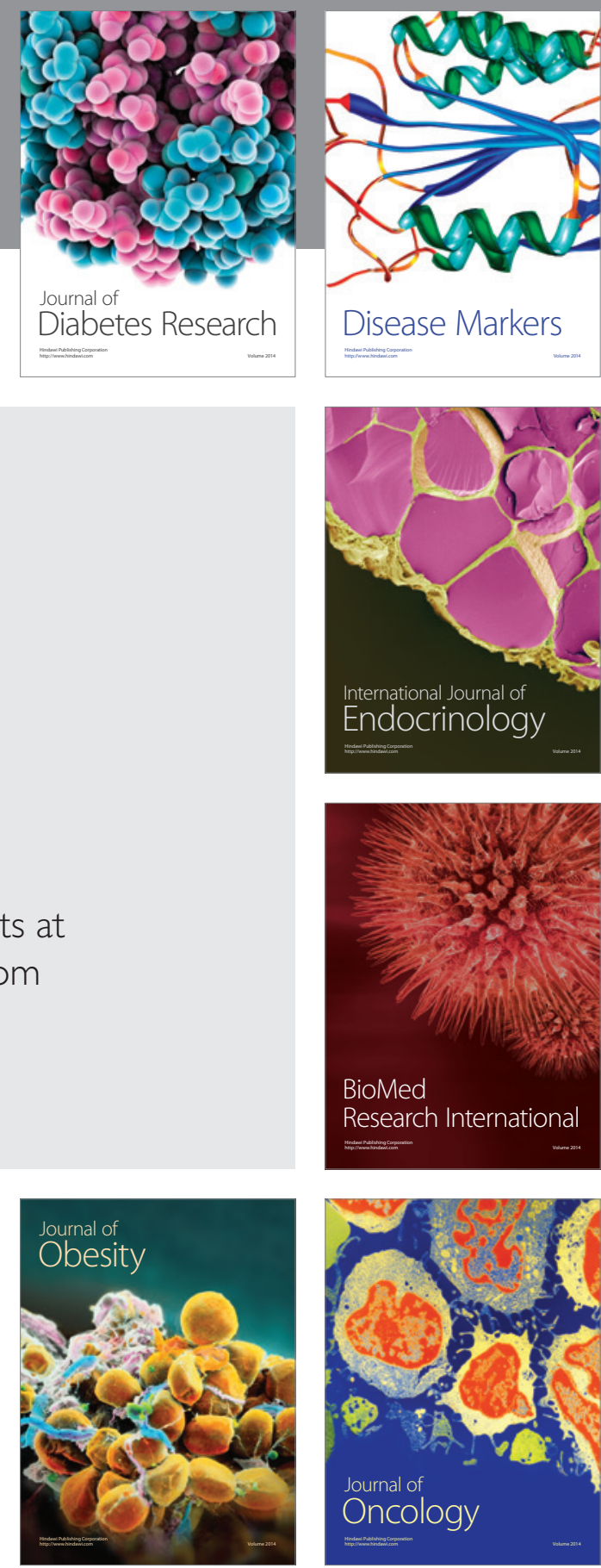

Disease Markers
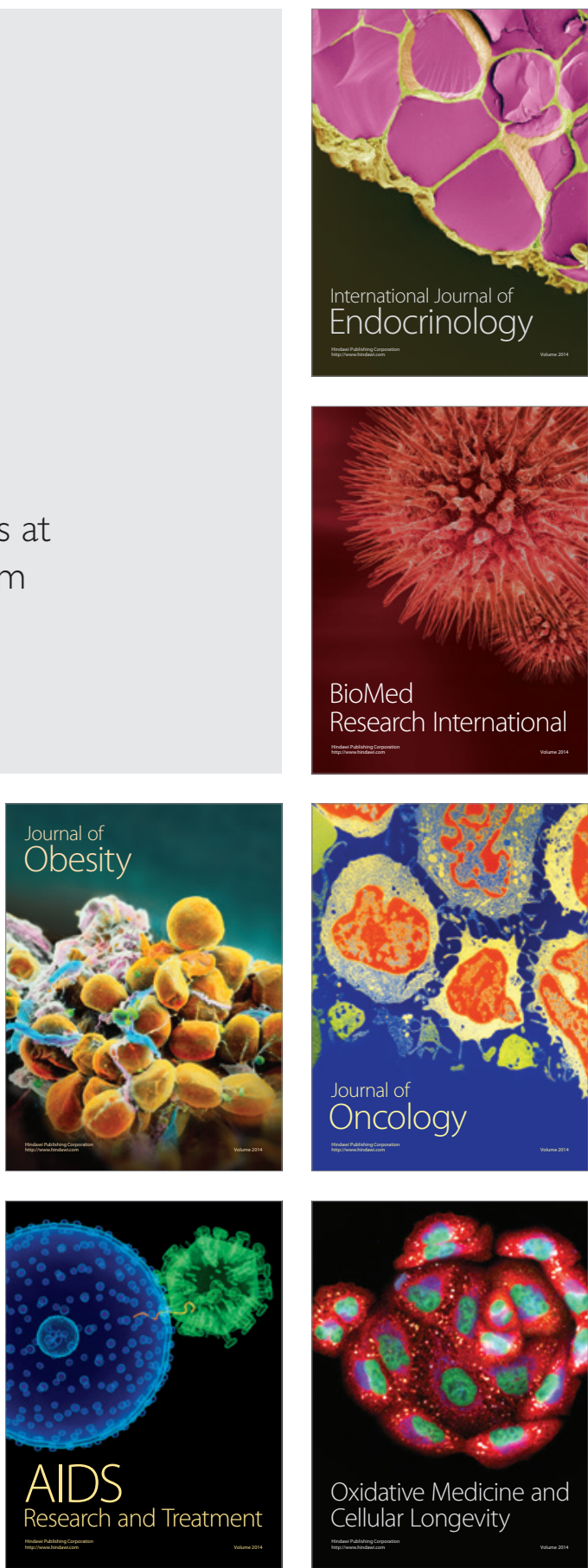